\title{
What if they Forget to Pay the Piper?
}

Tue newest budget from the United States Administration may be an intellectual masterpiece by combining acumen with information, but it is also a sombre document, full of evidence that people are now accustomed to living in a world in which expenditure on science and technology stagnates. It is true that nobody will miss the full flower of Plowshare, and that there may even be a kind of logic in the decision of the Atomic Energy Commission to finance the 200 $\mathrm{GeV}$ accelerator in Illinois at the expense of older and presumably duller projects, but the question now urgently arises whether it is really wise that the amount of money spent on uncommitted science and technology, and especially on basic research, should remain the same in the seventies as it became in the sixties. On the face of things, there is good reason for fearing that such a state of affairs will bring only trouble. More distantly, there is a serious risk that the continuing drain on the ebullience of the scientific community now in prospect will eventually bring about a condition in which industrialized society as a whole, not just the American, will languish.

This is why it is first important to count the blessings which the budget for 1971 contains. To begin with, there is the problem. For one thing, if $\mathrm{Mr}$ Nixon's people have their way with Congress, the National Science Foundation will have more to spend. That is as it should be, even if the increase is accompanied by a decrease in the amount of money for basic research provided by the other agencies-the Pentagon's Project Themis has now sunk without trace, and there will be very little surprise that it has now become necessary for NASA to give up its traditional but diminishing request for money with which to support university research. Putting the responsibility for the support of basic rescarch with the National Science Foundation is the right strategy, and doubtless it is no accident that the NSF has already begun to respond to the commendation by the National Science Board (the NSF's board of trustees) of a pattern of research financing in which good institutions are picked out for particular rewards. Yet there is a long way to go before the NSF can properly acknowledge that a large part of its responsibility is the support not merely of scientific research but of the institutions in which it is carried out. Before that can happen, Congress will have to acknowledge more openly that public money can be legitimately spent thus. A more radical change of pattern will only be possible when the NSF has more power to its elbow and more money in its purse.

In the meantime, the signs and symptoms of penury are plain for all to see. One important change has been the way in which many of the agencies have been forced to spend a greater proportion of their funds in their own laboratories. Among the obvious dangers of such a course are those of creating institutions which are less able to change with the times that the changing needs of scientific research require. American institutions may have been especially able to change their ways in the past few years, but there are limits to what is possible in tha face of adversity. A second and more serious problem is the way the new pressures may shift the initiative in research from the universities to the institutions. This is not so much a matter of scale as of temperament-a great many potential researchers may persuade themselves that life in a research institute may be preferable to life in a university when research is not considered to be an integral part of university life. But there is also the problem of scale. Nobody would find it easy to show in precisely what ways the generous spending on research and development in the decades since the Sccond World War has contributed to the present economic strength of the United States, but it would be a great surprise if the correlation was negative or even small.

But even economic strength is only a small term in the equation. The much more serious danger is that too much parsimony for too long may rob research of its capacity to sustain itself. The steam may condense in the cylinders. It may be too gloomy by half to fear that the comparatively gentle restrictions of the new budget could bring about such a tragedy. Yet it is also well known that modern science is substantially an invention of the past few decades. The budget men should sometimes ask themselves how much restraint for how long will be necessary to make it disappear all over again.

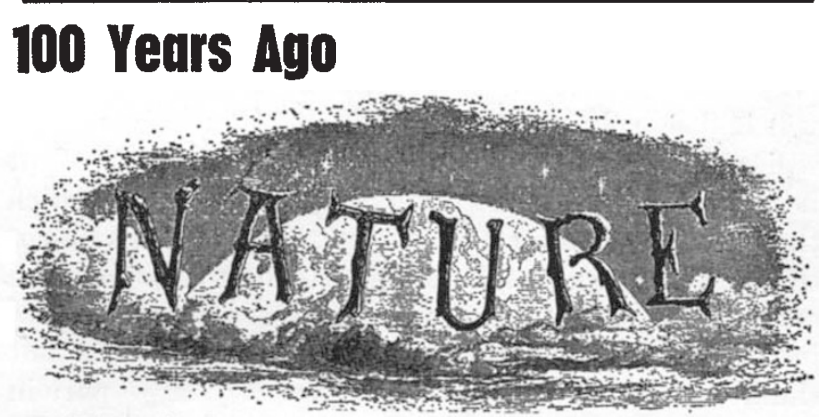

THE 25-inch Equatorial Telescope, commenced several years ago by T. Cooke and Sons, of York, for R. S. Newall, Esq., of Gateshead, is now so far completed that it has been removed from the works at York into its observatory in Mr. Newall's grounds, at Fern Deal.

The completion of a telescope with an object glass of 25 inches aperture, marks an epoch in astronomy, and its completion in England again places us in the front rank in the matter of the optical art, as we were in Dolland's time.

The history of the progress of the manufacture of telescopes since the time referred to, shows very clearly the long-lasting effects of bad legislation; for it is not too much to say that the duty on glass cntirely stifled, if indeed it did not kill, the optical art in England. Hence we depended for many years upon France and Germany for our telescopes to such an extent indeed that the largest object-glasses at Greenwich, Oxford, and Cambridge are all of foreign make.

From Nature, 1, 409, February 17, 1870. The instrument, described as a "monster among telescopes", sported a cigar. shaped tube 32 feet in length and weighed nearly 9 tons. 